\title{
Sistemas não-lineares, o método de Newton e Fractais
}

\author{
Fabio A. Dorini \\ Hellen C. Spengler* \\ E-mail: fabio.dorini@gmail.com, hellen.spengler@hotmail.com .
}

\section{Roy Wilhelm Probst}

E-mail: rwprobst@gmail.com.

Universidade Tecnológica Federal do Paraná, 80230-901, Curitiba, PR

\section{RESUMO}

\section{Introdução}

Nesse trabalho é abordado o método de Newton para sistemas não lineares do tipo $F(x)=0$, em que F é uma função de $\Omega \subset \mathbb{R}^{2}$ em $\mathbb{R}^{2}$. Além disso, com o auxílio do software Matlab há uma breve apresentação de um exemplo de implemetação do método, visando investigar interessantes formações de bacias de atração e fractais.

\section{Método de Newton}

O método de Newton tem por objetivo encontrar solução numérica de equações não lineares. O método consiste em linearizar e iterar esse passo até estar suficientemente próximo das raízes [1].

No caso de um sistema linear de uma equação, $y=f(x)$, objetiva-se determinar $x^{*} \in \mathbb{R}$ de modo que $f\left(x^{*}\right)=0$.

Geometricamente, dado $x_{0}$ uma aproximação inicial para $x^{*}$, observe que a reta tangente à curva $y=f(x)$ no ponto $\left(x_{0}, f\left(x_{0}\right)\right)$ é a linearização de $f$ nesse ponto. Logo, o ponto seguinte, $x_{1}$, será a interseção dessa reta com o eixo $x$ (solução de uma equação linear). Procurando generalizar o processo de iteração para $x_{k+1}$ tem-se que,

$$
\tan \theta=\frac{f\left(x_{k}\right)}{x_{k}-x_{k+1}}=f^{\prime}\left(x_{k}\right), \quad \text { ou seja, } \quad x_{k+1}=x_{k}-\frac{f\left(x_{k}\right)}{f^{\prime}\left(x_{k}\right)}, \quad(k=0,1, \ldots) .
$$

Entre as formas de parada para o método, é possível estabelecer uma tolerância $\epsilon$ que limite a diferença das iterações $\left(\left|x_{k}-x_{k-1}\right|<\epsilon\right)$ ou a própria função aplicada em $x_{k}\left(\left|f\left(x_{k}\right)\right|<\epsilon\right)$, em que $x_{k}$ é a solução procurada.

Agora, considere o conjunto de duas equações não lineares [2],

$$
f_{j}\left(x_{1}, x_{2}\right)=0, \quad j=1,2,
$$

em que as funções são não lineares. Usando notação vetorial para uma escrita mais concisa, o sistema formado por estas equações será representado por

$$
F(x)=0
$$

onde $x=\left(x_{1}, x_{2}\right)$ é um vetor coluna de variáveis independentes e $F(x)=\left(f_{1}(x), f_{2}(x)\right)$ é uma função vetorial de variáveis vetoriais.

*bolsista de Iniciação Científica PIBIC/CNPq 
Seja $x_{i}$ a i-ésima aproximação da solução e tomando $F_{i}$ por $F\left(x_{i}\right)$, o método de Newton define que

$$
\mathrm{x}_{i+1}=\mathrm{x}_{i}-A_{i}^{-1} F_{i},
$$

onde $A_{i}$ é a matriz jacobiana avaliada em $x_{i}\left(\partial f_{j} / \partial x_{k}\right)$.

Note que o processo de iteração é análogo ao problema de uma equação não linear, porém para obter a aproximação da solução é utilizada a série de Taylor de primeira ordem para funções vetoriais com variáveis vetoriais.

Procurando evitar a inversão da matriz jacobiana, faz-se necessária a resolução do sistema linear

$$
A_{i} v=-F_{i},
$$

em que $v=x_{i+1}-x_{i}$.

Nesse âmbito, tem-se a seguinte sequência de iterações,

$$
x_{i+1}=x_{i}+v,
$$

em que $x_{0}$ é a aproximação inicial.

\section{Resultados Numéricos}

Para um estudo preliminar, é considerado o seguinte sistema:

$$
\left\{\begin{aligned}
x^{3}-3 x y^{2}-1 & =0 \\
3 x^{2} y-y^{3} & =0 .
\end{aligned}\right.
$$

Observe que para diferentes pontos iniciais, o método de Newton converge, possivelmente, para diferentes soluções, que são associadas as cores conforme a tabela:

\begin{tabular}{cc}
\hline Soluções do sistema & Cores associadas \\
\hline$(1,0)$ & Amarelo \\
$(-1 / 2,-\sqrt{3} / 2)$ & Vermelho \\
$(-1 / 2, \sqrt{3} / 2)$ & Azul \\
\hline
\end{tabular}

A Figura 1 mostra as bacias de atração, formando um fractal.

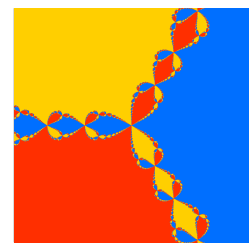

(a) $-2 \leq x, y \leq 2$

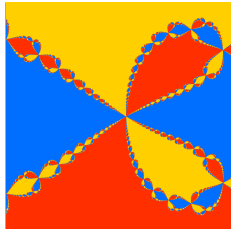

(b) $-1.75 \leq x \leq-1.15,-0.3 \leq y \leq 0.3$

Figura 1: Bacias de atração das soluções do sistema (1)

Palavras-chave: Sistemas não-lineares, Método de Newton, Fractais

\section{Referências}

[1] M. C. C. Cunha, "Métodos Numéricos", 2. ed., Campinas: UNICAMP, 2000.

[2] C. G. Broyden, A Class of Methods for Solving Nonlinear Simultaneous Equations, Mathematics of Computation, 19 (1965) 577-593. 